\title{
Naturaleza, identidad y rebeldía en La ciudad de las damas de Christine de Pizan
}

\section{Introducción}

La obra de Christine de Pizan (1364-1430), veneciana de nacimiento e hija del astrólogo de Carlos V de Francia, se inserta dentro de la llamada Querelle des femmes, movimiento que eclosionó en Europa a finales del siglo XIII, en un período que sella el paso de la Edad Media a la cultura renacentista. Casada a los quince años, madre de tres hijos y pronto viuda, aprovechó la educación recibida de su padre para defender el valor y la dignidad de las mujeres. La Querella estalla cuando Jean de Meun añade al Roman de la Rose de Guillaume de Lorris (1225) una serie de páginas fuertemente misóginas. La protesta arraiga en la Universidad, hace fortuna en las Cortes europeas y el debate llega hasta la Revolución Francesa. Más allá de su valor simbólico, este movimiento reavivó la discusión entre defensores y detractores del sexo femenino. Cuando Christine de Pizan escribe el libro de La ciudad de las damas, lega a la posteridad una obra que se opone al mundo construido por los hombres, una sociedad que se caracterizaba por el egoísmo y la falta de equidad. Siempre supo que los defectos que el orden patriarcal atribuía a su sexo no eran fruto de una descripción objetiva, sino que obedecían a intereses que tal vez reflejaran "el miedo de los hombres que mandan sobre las mujeres". ${ }^{1}$ Aunque en un principio concibe su ciudadela como refugio frente a la agresión, sus murallas han sido definidas como una ginetopia, esto es, un espacio simbólico que consiente a la mujer superar los modelos sociales que la subordinan al hombre. ${ }^{2}$ A nuestro entender, La ciudad de las damas es una obra singular en tanto se nos presenta como la expresión de quien se atrevió a implicarse en ámbitos relevantes de la vida pública. Nuestra escritora imagina una comunidad de mujeres que rechaza la ortodoxia patriarcal y discute los modos de relación de los sexos. Su libro trata de redefinir la naturaleza femenina confiriendo a la mujer idéntica capacidad intelectual que al hombre y prácticamente las mismas virtudes. Niega la subordinación ética frente al varón y con

1 E. Laurenzi, Christine de Pizan, ¿una feminista “ante litteram”?, en "Lectora”, 15, 2009, pp. 301-314, p. 309.

2 M. M. Rivera Garretas, Textos y espacios de mujeres, Barcelona, Icaria, 1990, p. 195.

María Elena Ojea Fernández, UNED-Ourense

Ә Open Access. (C) 2018 María Elena Ojea Fernández, published by De Gruyter. (c) BY-Nc-ND This work is licensed under the Creative Commons Attribution-NonCommercial-NoDerivatives 4.0 License. https://doi.org/10.1515/9783110596755-016 
gran habilidad propone una sociedad nueva que permita a las mujeres pensar y actuar según su propia naturaleza. Al tiempo que cuestiona el orden patriarcal, fija su atención en la identidad femenina, una identidad despreciada y percibida siempre en negativo. Su rebeldía parte de la convicción de que la mujer es una pieza esencial en el engranaje social, de manera que no se le puede prohibir el acceso al conocimiento. La creación de ese espacio para damas sabias es una manifestación de orgullo y una fuente de liberación frente a la misoginia imperante. Se propone una ciudad utópica que ha de servir como ejemplo de integración, pues se trata de un sistema que no excluye. El meticuloso trabajo de la autora francesa socava las leyes escritas que presentaban a la mujer como una anomalía y le impedían alcanzar la libertad a la que por naturaleza tenía derecho. La gran pensadora interviene en la polémica para reflexionar acerca de la sociedad de su tiempo. Todo ello supone transgredir la regla del gran silencio, norma omnipresente en el mundo cristiano y patriarcal. Pero Pizan desestima el lenguaje heredado y crea uno propio, que designa un universo nuevo, innovador y pleno de significado.

\section{Naturaleza femenina}

La ciudad de las damas es una obra que trata de contrarrestar la misoginia imperante con un alegato en defensa de las cualidades femeninas. Son singulares las ideas de su autora acerca de la naturaleza humana. A su juicio, Dios quiso que hombres y mujeres le sirviesen de forma distinta. Si a los hombres otorgó fuerza física, a las mujeres bendijo con una naturaleza sensible que rechaza el uso de la fuerza y el poder de las armas. Pizan cree que las mujeres jamás podrían recurrir a la violencia para hacer respetar las leyes, ${ }^{3}$ si bien reconoce que hay damas cuyas dotes de mando superan las del hombre más versado. Respalda su teoría recurriendo a Nicaula, la emperatriz que reinó sobre un vasto imperio y cuya sabiduría fue tan legendaria que mereció la aprobación de la Biblia. De Nicaula celebra su fortaleza de carácter y la decisión de gobernar en solitario: "Era muy entendida en el arte de las letras y de las ciencias, y tan altiva que nunca se casó ni quiso tener hombre alguno a su lado". ${ }^{4}$ Nuestra erudita estima la naturaleza femenina tan digna de elogio que no duda en ensalzar su firmeza y su sentido del decoro. Nada extraño si reparamos en la férrea vigilancia de la sexualidad y en lo fácil

3 Ch. de Pizan, La ciudad de las damas, edición de Marie-José Lemarchand, Madrid, Siruela, 1995, p. 30.

4 Ibid., p. 32. 
que era ser repudiada por simples rumores. Los elogios a la castidad de Zenobia de Palmira que "se acostaba con su marido solo para asegurarse una descendencia y se lo daba a entender prohibiéndole dormir a su lado en cuanto se quedaba embarazada", 5 no pasan desapercibidos, como tampoco su defensa incondicional de Semíramis, que desposó a su hijo para impedir que ninguna otra mujer llevara la corona del imperio, hecho que excusa de forma poco convincente:

Aquello obedeció a dos razones: la primera, para que ninguna otra mujer llevara la corona del imperio, lo que hubiera sido el caso si su hijo se hubiera casado con otra, la segunda, que ningún hombre le parecía digno de compartir su lecho. Ciertamente, fue una falta grave pero excusable puesto que todavía no regían las leyes escritas. Como entonces la gente no conocía otras leyes que las de la Naturaleza, cada uno podía dejarse llevar del placer sin culpa. ${ }^{6}$

La escritora francesa cree que el modo de ejercer la libertad femenina viene dado por una mezcla de vigor y dulzura; así pues, tanto aplaude que las amazonas recurran a la violencia para alcanzar sus fines, como agradece que Dios haya dado a la mujer debilidad física si de ello puede salir beneficiada: "Gracias a este defecto que tampoco es muy ingrato, no tienen que cometer horribles torturas". ${ }^{7}$ Las damas que escoge para demostrar la solidez de la conducta femenina son célibes y altivas, como la duquesa de Anjou, que prefirió la virginidad y no se juntó nunca con un hombre. ${ }^{8} \mathrm{Y}$ aunque aparentemente siga las directrices del patriarcado, también saca a relucir que es la mujer y no el varón, - al que con frecuencia tilda de disoluto - quien guarda los preceptos exigidos. Su dialéctica desafía con sutil desdén las falacias de los textos oficiales, que no muestran la verdadera imagen de la mujer, sino el "retrato interesado que los hombres hacen de ella". 9

Christine de Pizan basa su trabajo en las diferencias de comportamiento entre hombres y mujeres. Sostiene que la mente femenina siempre se ha caracterizado por la constancia y la lealtad, mientras el juicio del varón, - siempre airado y bien dispuesto a creer la calumnia - , se permite humillar a la mujer poniendo a prueba constantemente su fidelidad. Cuando relata el saber y la

5 Ch. de Pizan, cit., p. 53.

6 Ibid., p. 38.

7 Ibid., p. 35. De la misma opinión fue Concepción Arenal en el s. XIX, para quien: "La mujer, que domina por la persuasión, la dulzura y el cariño, no ha nacido para mandar por medio de la fuerza, sufre donde hay necesidad de coacción" (C. Arenal, La mujer del porvenir. Obras completas, Vigo, Ir-Indo, 2000, II, p. 108.

8 Ibid., p. 40.

9 G. Duby, El modelo cortés, en G. Duby - M. Perrot (eds.), Historia de las mujeres 2. La Edad Media, Madrid, Taurus, 2006, pp. 319-339, p. 324. 
inteligencia de otras mujeres, lo que pretende es subrayar que vive acompañada del recuerdo de damas excepcionales que quebrantaron las normas como hace ella ahora.

\section{El signo de la diferencia en un orden de desigualdad}

La realidad doméstica en la Europa medieval dibujaba un cuadro sombreado de humillaciones y ofensas que una mujer tenía la obligación de soportar estoicamente. La larga tradición misógina que incluía a ilustres como Agustín de Hipona, Jean de Meun o el Arcipreste de Talavera dictaba un sistema de valores que forzaba a las mujeres a vivir pendientes del bienestar masculino, siempre "desplazadas de sî”. ${ }^{10}$ Como el matrimonio no era más que un férreo mecanismo de control, muchas damas de mérito se refugiaron en el voto de castidad y en la soledad del convento. El mismo orden simbólico que condenaba la sexualidad femenina, se ocupaba de mortificar psíquicamente a la mujer, a la que consideraba una extraña. ${ }^{11}$ La concepción del matrimonio como una cárcel donde la esposa recibe peor trato que las "esclavas de los moros"12 es una cadena que enlaza el pensamiento de Pizan con el talento autodidacta de Olympe de Gouges, quien siglos más tarde definiría la vida conyugal como la "tumba del amor y de la confianza". ${ }^{13}$

Uno de los aspectos más interesantes de La ciudad de las damas radica en el rechazo de Pizan a los papeles que el patriarcado asigna a las féminas. Sus argumentos llaman la atención por su firmeza y modernidad, como la negativa a aceptar la supuesta frivolidad del sexo femenino en un tema tan grave como la violación. Pizan se apoya en la antigüedad para demostrar que el sufrimiento obligaba a muchas mujeres a urdir estratagemas para librarse de ser violentadas. ${ }^{14}$ A la marginación general responde nuestra humanista con la propuesta de un espacio exclusivo para damas cultas, una especie de mundo aparte que sirve de fortín frente a la hostilidad patriarcal. Christine evoca una ciudad de

10 M. M. Rivera Garretas, Nombrar el mundo en femenino: pensamiento de las mujeres y teoría feminista, Barcelona, Icaria, 2003, p. 103.

11 C. Opitz, Vida cotidiana de las mujeres en la Baja Edad Media (1250-1500)”, en Historia de las mujeres, cit., pp. 340-410, p. 349.

12 Ch. de Pizan, Christine de Pizan, ¿una feminista “ante litteram”, cit., p. 119.

13 L. Manzanera, Olympe de Gouges, una feminista avanzada, en "Historia National Geographic", 155, diciembre de 2016, pp. 12-16, p. 12.

14 Ch. de Pizan, cit., pp. 156, 159, 160. 
hermanas y amigas, no de familias, ${ }^{15}$ observación que pone de manifiesto el carácter incómodo, incluso subversivo de su texto. El retiro a un espacio libre de ataduras prescindiendo de la voz de los hombres cultos y de su "curiosa misoginia”, ${ }^{16}$ define una personalidad sólida, empeñada en lograr la identidad literaria a partir de su Yo femenino. Su actividad nada tiene que ver con el sedentarismo tradicional de las mujeres, cuyo único desplazamiento permitido era la entrega en matrimonio. ${ }^{17}$ La autora escribe un texto que bebe en las fuentes de su experiencia privada, de ahí que nos encontremos ante un libro autobiográfico, ${ }^{18}$ una obra introspectiva, donde se hace visible la realidad de su persona. Christine es consciente de que su existencia, como la del resto de las mujeres, está supeditada a dar, no a recibir. Si cumple las normas, recibirá el mayor galardón, de lo contrario será castigada de manera ejemplar, no solo por los hombres, también por las mujeres buenas, aquellas que como doña Sancha, la madre de los siete infantes, se erigen en ejecutoras de la ideología masculina. ${ }^{19}$ Las mujeres buenas son aquellas cuyos actos persiguen la armonía social: no hablan ni discuten porque están en silencio. Pizan no solo rechaza estos arquetipos, sino que su agudo olfato es capaz de percibir el temor ancestral a la mujer libre y emancipada. El varón, que se comporta como padre, maestro y propietario, perfila para la mujer el papel de guardiana eterna de los valores inmutables de la sociedad. $Y$ es que la existencia femenina transcurría bajo la atenta vigilancia de la cultura patriarcal, que la representaba como santa o pecadora. ${ }^{20}$ Las mujeres del tiempo de nuestra filósofa, incluso las de clase alta, tenían su espacio reservado en la administración del hogar, en la despensa o en la costura. El mundo femenino se ubicaba entre los hilos de seda: mujeres solas o en compañía de otras mujeres "creando un lenguaje propio". ${ }^{21}$ Las tareas domésticas las alejaban de la ociosidad peligrosa, germen de toda tentación, pues su verdadera razón para existir era servir al hombre y traer hijos al mundo. Pero la erudita francesa rechaza el discurso oficial que anula abruptamente la subjetividad femenina. Discute el ideario que describe a la mujer como un ser proclive al miedo, insegura, profundamente maleable, débil y privada de firmeza. Ella misma, que sufrió los improperios del

15 M. M. Rivera Garretas, Textos y espacios de mujeres, cit., p. 197.

16 Ibid., p. 29.

17 Ibid., p. 39.

18 M.A. Holguera Fanega, Christine de Pizan, la autobiografía femenina en la Edad Media, en Escritura autobiográfica, J. Romera et al. (eds.), Madrid, Visor Libros, 1993, pp. 259-265, p. 259.

19 M. E. Lacarra, Representaciones de mujeres en la literatura española de la Edad Media (escrita en castellano), en Breve historia feminista de la literatura española escrita (en lengua castellana), I. M. Zavala (coord.), Madrid, Anthropos, 1995, vol. II, pp. 21-68, p. 52.

20 J. Varela, Nacimiento de la mujer burguesa, Madrid, La Piqueta, 1997, p. 165 y ss.

21 A. Caso, Las olvidadas. Una historia de mujeres creadoras, Barcelona, Planeta, 2005, p. 71. 
régimen patriarcal, constituye un ejemplo a seguir. A través de su Libro, crea un espacio protector que une a las mujeres de mérito en torno a un objetivo común:

\footnotetext{
Honorables damas, alabado sea Dios porque queda terminada la construcción de nuestra Ciudad que os acogerá a todas. Vosotras que os preciáis de virtud, dignidad fama, seréis bien acogidas en una Ciudad levantada y edificada para todas las mujeres de mérito, las de ayer, hoy y mañana. ${ }^{22}$
}

Nuestra pensadora busca un símbolo que devuelva la imagen y la humanidad a la mujer. Lo encuentra en la figura de la Virgen María a la que otorga un rol activo, como antes había hecho Bernardino de Siena, quien entendía que la Virgen "no constituye solamente ser, no es únicamente pasividad femenina previa al acto divino o a la contemplación estética, sino potencia". ${ }^{23}$ Entonces, la Virgen es ese alguien que estampa su imagen a Dios y otorga voz y rostro a quien no lo posee. Pizan utiliza esa imagen poderosa para rehabilitar a su sexo, dado que María era el único referente válido de comparación y el único espejo en el que mirarse.

\section{La mujer, sujeto no histórico}

Christine de Pizan defendía que la invención del mundo pasaba por las manos y por la experiencia de la mujer. Era consciente de las posibilidades intelectuales de sus congéneres y las exhortó a aceptar el desafío que supone usar la palabra, pues sabía que la voz de "aquellas que saben leer y escribir dejará aflorar durante mucho tiempo el temor de las audacias y el miedo de las impotencias". ${ }^{24}$ La palabra es un bien precioso y las damas doctas deben servirse de ella para probar su sabiduría, pero también para honrar a quienes las precedieron, a las grandes olvidadas, a las que "descubrieron mucho antes que nosotras que la Historia ha sido fabricada por los hombres, por los hombres de las castas superiores para provecho de los hombres de las castas superiores". ${ }^{25}$ Christine de Pizan recomendaba encarecidamente no ceder ante la perfidia de quienes acusan a las mujeres de los vicios más abyectos: “iquitadles las máscaras, que

22 Ch. de Pizan, cit., p. 230.

23 N. Catelli, El espacio autobiográfico, Barcelona, Lumen, 1991, p. 102.

24 D. Règnier-Bohler, Voces literarias. Voces místicas, en Historia de las mujeres 2. La Edad Media 2, Madrid, Taurus, 2006, pp. 473-546, p. 491.

25 M. Roig, "Prólogo" (1 $1^{\text {a }}$ ed. 1978, p. 11), en A. Rodrigo, Mujeres para la historia. La España silenciada del siglo XX, Barcelona, Ediciones Carena, 2002. 
nuestras brillantes cualidades demuestren la falsedad de sus ataques!" ${ }^{26} \mathrm{Ha}$ sido el orden sociosimbólico el culpable de cercenar el acceso de las mujeres al poder. También el que ha mermado su autoestima y su dignidad con opiniones misóginas que se mantienen inalterables en el tiempo. La cultura patriarcal aniquiló la memoria femenina a fuerza de control, encierro y silencio. Oscuros intereses propiciaron la animadversión en los centros del saber, allí donde el talento femenino despertó siempre indiferencia. La lucha por la emancipación femenina ha sido un camino lleno de dificultades. Las obras de las mujeres notables escasean en la memoria colectiva y en la historiografía oficial. Y, sin embargo, la mujer contribuyó al desarrollo intelectual tanto como el hombre, y aun al refinamiento del lenguaje, como ocurrió con las preciosas en los salones parisinos del siglo XVII. Fue la larga sombra del descrédito la que obligó a retroceder a muchas damas de talento. Madame de La Fayette, autora nada menos que de La princesa de Clèves, editaría anónimamente su obra pese a los rumores que apuntaban a su autoría. De ahí que sea tan importante el esfuerzo de Christine de Pizan, que divulga su pensamiento en una obra comprometida, individual, muy ligada a su condición de mujer y que perfectamente consciente de su trascendencia cede a la posteridad.

La cultura patriarcal no ofreció a la mujer - incluso en los países más avanzados - más que aquello que satisfacía las necesidades del varón. El matrimonio constituía la institución ideal para dominar el cuerpo de las hembras, pues a través de la sexualidad se logra la "naturalización del desequilibrio de poder entre los sexos". ${ }^{27}$ La mujer encerrada, apartada del mundo y en perpetuo silencio es el ideal femenino de un orden que no dio tregua: "Que nos guste, que se calle, que se quede en casa”. ${ }^{28}$ Tal vez por ello, Pizan recomienda no limitarse a los espacios y a los saberes domésticos. Su objetivo consiste en luchar por un mundo donde sea posible recuperar la propia realidad y sentirse libre y respetada.

Cuando nuestra humanista rebate públicamente una normativa de siglos, la llamada auctoritas masculina, no solo está llevando a cabo un acto transgresor de gran alcance, ${ }^{29}$ sino que con ello devuelve a su sexo la dignidad que le ha sido negada. Para la erudita francesa, la memoria alberga el archivo de la cultura femenina. Recurre a las antepasadas porque estima de vital importancia compartir el conocimiento para trazar el futuro, pues en palabras de Susan Stanford

26 Ch. de Pizan, cit., p. 231.

27 J. Varela, cit., p. 193.

28 Pío X resume el carácter de la ideología patriarcal con esta frase. R. Levi-Montalcini, Tiempo de cambios, Barcelona, Península, 2005, p. 45.

29 A. Vargas Martínez, en La querella de las mujeres. Tratados hispánicos en defensa de las mujeres (siglo XV), Madrid, Editorial Fundamentos, 2016, p. 229. 
Friedman "la pérdida de las memorias colectivas, de miríadas de historias sobre el pasado han contribuido enormemente a la vigente subordinación de las mujeres". ${ }^{30}$ El Libro de Pizan resulta entonces un proyecto profundamente transformador en cuanto impulsa la difusión y la expansión de la Querella y reta abiertamente al mecanismo patriarcal de control, responsable de la desvalorización de las mujeres y de lo femenino.

\section{Conclusión}

La obra de Christine de Pizan se nos antoja un cuadro renacentista, un fresco repleto de mujeres en cuyas vidas se concentra el hallazgo de la identidad femenina. La representación de personalidades famosas tenía en el Quattrocento la intención de recordar a las generaciones futuras no solo la fama sino también los ideales éticos de los representados. La amplia selección de damas ilustres explica el mensaje clave de la obra: "no hay mejor morador para una ciudad ni mayor hermosura que unas mujeres valiosas". ${ }^{31}$

La ciudad de las damas es un alegato enérgico en el que su autora plantea el problema de la exclusión de sus congéneres de forma crítica y reflexiva. Su discurso entiende la solidaridad del nosotras las mujeres, como única vía de ver respetada la identidad femenina. Los últimos siglos de la Edad Media se distinguieron por el juicio desdeñoso en torno a la figura y al "impetuoso torrente de lengua de las mujeres". ${ }^{32}$ La ideología oficial no estaba dispuesta a permitir que una dama con ideas propias se sintiera con valor para hablar en público. De todo ello toma nota la autora, que se encomienda a la Virgen para liberar a las mujeres del mal ontológico que se les atribuye. Su homenaje a María está cargado de simbolismo, pues de la Virgen emana una imagen positiva de la mujer y de su feminidad. Aunque la sociedad patriarcal sostiene que las mujeres solo pueden alcanzar la salvación por medio del arrepentimiento, la escritora defiende que la naturaleza femenina no es maligna y señala como responsable de la desigualdad de género a la perversa dialéctica varonil acerca de la superioridad / dominación, inferioridad / sumisión. En su Libro apela a la fuerza innovadora del Evangelio, que proclama la igualdad de todos los seres humanos ante Dios. Defiende que la mujer tiene alma y que no fue creada como una mala copia ni como un ser subalterno al hombre, mal que pese a los moralistas. Los muros de su ciudad utópica

30 K. Offen, Feminismos europeos, 1700-1950. Una historia política, Madrid, Akal, 2015, p. 49.

31 Ch. de Pizan, cit., p. 118.

32 J. Dalarun, La mujer a los ojos de los clérigos, en Historia de las mujeres, cit., pp. 41-71, p. 69. 
tienen la misión de proteger a las féminas de la tentación de las interpretaciones interesadas que solo aspiran a amordazarlas bajo el lema de la humildad, la mansedumbre y la obediencia. Pizan advierte que solo un cambio radical en la sociedad podría beneficiarse de la ingente y muchas veces silenciosa labor intelectual de la mujer. En fin, la grandeza de esta erudita radica en haber sido capaz de mantener la independencia en un ambiente particularmente adverso, pues como mujer estaba excluida de la historia oficial del pensamiento. Los filósofos y científicos, incluidos los que luego serían calificados de "ilustrados", alimentaron el mito de la superioridad masculina. Pero nuestra filósofa prueba que las mujeres han contribuido al desarrollo del conocimiento en la misma medida que el hombre. Las personalidades femeninas que recorren su obra confirman que el raciocinio es un atributo de la especie humana sin distinción de sexo. Su empeño porque las mujeres disfrutaran del derecho a utilizar sus capacidades intelectuales la convierte en pionera de la igualdad natural de los sexos. 